\title{
Intervenção nas universidades: Cortes de verbas e imposições legais
}

\author{
Intervention in universities: Cuts in budgets and legal impositions
}

\begin{abstract}
Sandra de Castro de Azevedo Professora Doutora em Geografia, Universidade Federal de Alfenas- UNIFAL-MG, Brasil sandra.azevedo@unifal-mg.edu.br

Roberto Mauro da Silva Fernandes Professor Doutor em Geografia, Professor Visitante do PPGeo- UNIFAL-MG Brasil robertomauro.fernades@hotmail.com

Abigail Bruna da Cruz Licenciada em Geografia e Mestranda do PPGeo-UNIFAL-MG Brasil Bolsista da Coordenação de Aperfeiçoamento de Pessoal de Nível Superior (CAPES) abigail.cruz@sou.unifal-mg.edu.br
\end{abstract}

\begin{abstract}
Resumo
A autonomia da universidade garantida por meio da lei, está sendo ameaçada e esse processo se intensifica em um governo de extrema direita que se manifesta publicamente contra as universidades públicas e contra o servidor público. Para auxiliar na compreensão deste contexto, esse texto abordará a expansão do ensino superior no Brasil que se inicia em 2005 para evidenciar como a mudança do bloco do poder no governo, modifica o projeto e inicia uma política de intervenção nas universidades, seja por meio de cortes de verbas que inviabilizam muitas ações e também a intervenção por meio de políticas públicas aprovadas em forma de diretrizes e editais que atacam a autonomia da universidade. Para exemplificar esse movimento será feita uma análise pautada nos cursos de licenciatura que apresentam uma complexidade por estar vinculados a profissões desvalorizadas socialmente e financeiramente e que normalmente são oferecidas no período noturno para atender os alunos da classe trabalhadora que são provenientes de uma educação pública deficitária. A profissão docente é um espaço de disputa onde se enfrentam os defensores de uma formação ampla do profissional pautada em elementos que valorizam uma visão humana e emancipadora e os defensores de uma formação técnica que atende o mercado. No cenário político atual essa visão técnica está vencendo a disputa e está sendo imposta por meio da BNC-Formação que é uma Diretriz de formação de professores que impõem elementos relacionados a organização curricular e a avaliação dos cursos. A autonomia da universidade está ameaçada por diretrizes e editais que destinam verbas para esses cursos, desde que os mesmos atendam às exigências que estão articuladas. Diante deste cenário é importante estar atento e organizar estratégias de enfrentamento.
\end{abstract}

Palavras-chave: Ensino Superior; perda de autonomia; investimentos; precarização da formação inicial e continuada.

\begin{abstract}
The university's autonomy guaranteed by law is being threatened. This process intensifies in a farright government that publicly speaks out against public universities and civil servants. To assist in understanding this context, this text will address the expansion of higher education in Brazil that begins in 2005 to show how the change in the government's power bloc modifies the project and initiates an intervention policy in universities either through cuts in funds that make many actions unfeasible and also intervention through public policies approved in the form of guidelines and public notices that attack the university's autonomy, to exemplify this movement, an analysis will be carried
\end{abstract}


out based on licensure courses that present a complexity for being linked to socially and financially devalued professions and that is normally offered at night to attend working-class students who come from a deficient public education. The teaching profession is a space of dispute where defenders of broad professional training are faced, based on elements that value a human and emancipatory vision and advocates of technical training to supply the job market. In the current political scenario, this technical vision is winning the dispute. It is being imposed through the BNC - Formação, a teacher education Guideline that imposes elements related to curriculum organization and course evaluation. On the other hand, the university's autonomy is threatened by guidelines and notices that allocate funds for these courses, provided they meet the articulated requirements. In this scenario, it is important to be aware of and organize confrontation strategies.

Keywords: University education; loss of autonomy; investments; precariousness of initial and continuing education.

\section{INTRODUÇÃO}

As crescentes intervenções políticas sobre a universidade visando o desmanche e o controle das instituições públicas de ensino superior é um tema relevante a ser refletido, ainda mais no âmbito das ciências humanas e sociais, onde esse processo é mais agravado devido seu viés de formação inicial e continuada estabelecerem uma crítica mais acentuada aos processos políticos e sociais que cercam a sociedade.

Pesquisar e escrever sobre a intervenção nas instituições federais de ensino superior é uma forma de resistir e enfrentar um projeto de desmonte do ensino e da pesquisa no Brasil. Esse artigo tem como objetivo compreender os processos de intervenção nas universidades federais e suas consequências no funcionamento das mesmas. Para alcançar esse objetivo o caminho metodológico realizado utilizou levantamento e análise de material bibliográfico, análise documental e análise de dados secundários.

Este texto está organizado em três etapas, na primeira é apresentada a expansão do ensino superior no Brasil, e as diferentes formas que essa expansão ocorreu, considerando PROUNI, UAB e REUNI, o que evidencia que em um momento da história recente do nosso país o ensino superior e a ciência eram prioridades. Na segunda etapa é evidenciado a mudança de projeto para o ensino superior no Brasil, causado pela mudança no bloco de poder do governo, quando os cortes de verbas para as instituições superiores e para a ciência se tornaram algo presentes todos os anos. E na terceira e última etapa é exemplificado como os ataques às universidades podem ocorrer por meio de políticas aprovadas pelo governo federal. Para isso foi analisado as políticas que norteiam os cursos de formação de professores, área que se encontra em forte disputa entre uma educação para o mercado pautada nos preceitos neoliberais defendidas pelo governo atual e a resistência e enfrentamento por uma educação emancipatória. 
Defender a universidade pública é defender ensino, pesquisa e extensão que são essenciais para a sociedade. Ao cortas verbas e controlar as ações das universidades o governo interfere em serviços que são oferecidos para os sujeitos que ingressaram na universidade e também para a população que usa serviços de saúde, educação e cultura que são oferecidos para toda a população. Resistir e enfrentar é preciso.

\section{A EXPANSÃO DO ENSINO SUPERIOR (GOVERNOS LULA E DILMA): LEMBRETE}

O governo de Fernando Henrique Cardoso (1995-2002) foi marcado pela redução dos investimentos na educação superior. Assim, após quase uma década de cortes orçamentários e escassos investimentos nas Instituições Federais de Ensino Superior, o governo federal, sob o comando de Luís Inácio da Silva, iniciou um planejamento de expansão da universidade pública no Brasil. O processo de expansão e restruturação do ensino superior ocorreu em duas etapas, a primeira entre os anos de 2003 e 2006 e a segunda etapa teve início no ano de 2007, primeiro ano do segundo mandato do presidente Lula.

A primeira fase de expansão do ensino superior no Brasil tinha como objetivos criar Instituições Federais de Ensino Superior (IFES) e quarenta novos campi a partir de um processo de interiorização das IFES. Nesse contexto dois programas merecem destaque: 1) programa Universidade Aberta do Brasil (UAB) e 2) Programa Universidade para Todos (PROUNI).

O Programa Universidade para Todos (PROUNI), instituído pela Lei n ${ }^{\circ} 11.096 / 2005$, foi criado com a finalidade de conceder bolsas de estudos integrais e parciais a estudantes de cursos de graduação e sequenciais, em universidades privadas de educação superior. Uma forma de expansão da educação superior por meio de financiamento estatal via instituições privadas de ensino. $\mathrm{O}$ PROUNI possibilitou a abertura de inúmeras vagas em cursos noturnos, com objetivo de beneficiar a classe trabalhadora (MANCEBO, 2015).

A Universidade Aberta do Brasil (UAB), programa lançado em 2006, tinha como meta expandir e interiorizar a oferta de cursos de educação superior no Brasil. A prioridade estava na expansão de cursos de licenciatura e de formação inicial e continuada de professores para atender demanda da rede pública de educação básica. De acordo com Carvalho (2013), no âmbito da UAB foi criado o programa pró-Licenciatura para contemplar docentes em exercício na educação básica pública que atuavam há, pelo menos, um ano sem habilitação legal para exercer a função, esses cursos seriam oferecidos em conjunto com a União e seus entes federativos por intermédio de instituições públicas de educação superior. 
É importante destacar que esse processo de ampliação de oferta de curso superior favoreceu as universidades privadas por meio do Prouni e a modalidade de educação a distância por meio da UAB, só posteriormente foi fortalecido a educação superior pública.

Aproveitando a publicação do Plano de Desenvolvimento da Educação (PDE), o governo federal lançou, através do decreto n ${ }^{\circ}$ 6.096/2007, o Programa de Apoio a Planos de Reestruturação e Expansão das Universidades Federais (REUNI). Tratava-se da ação inicial da segunda fase de expansão das universidades federais, na época o Ministério da Educação estava sob o comando de Fernando Haddad.

Englobando as duas fases, foram criadas duas novas universidades (vinte e cinco campus universitários) na região Norte; no Nordeste foram instaladas seis novas universidades (e cinquenta e um campus; uma universidade (oito campi) no Centro-Oeste; três no Sul (e trinta e seis campi) e duas IFES no Sudeste (e vinte e sete campi) (ALMEIDA, 2017).

As duas etapas de expansão promoveram uma ampliação significativa do número de vagas nos cursos presenciais de graduação nas universidades federais, totalizando no ano de 2012 um número de 239.942 vagas, um aumento de 120\%, frente a disponibilidade em 2003 que era de 109.184. Nesse contexto, o Reuni foi o maior responsável pelo aumento expressivo de vagas, contabilizando a criação de cerca de 100.000 novas oportunidades de acesso às universidades públicas. Um aspecto importante a ser mencionado é que a expansão focada na interiorização da educação superior pública tinha como escopo 1) reduzir as desigualdades de oferta de vagas em diferentes regiões do país; 2) fortalecer a educação do país fora da Região Concentrada e 3) contemplar camadas da população que até aquele momento estavam excluídas do acesso à educação superior (CARVALHO, 2015; ALMEIDA, 2017)).

Ademais, a interiorização ampliou o quantitativo de matrículas, entre os anos de 2002 e 2013, houve um aumento de $98 \%$ do número de alunos matriculados no interior dos estados (UF), número bem superior ao montante registrado nas capitais que girou em torno de $63 \%$ (RIBEIRO e LEDA, 2015). O REUNI foi o responsável pelo aumento de 60,05\% das matrículas presenciais na rede federal, entre 2007 e 2012. Por outro lado, o programa buscou diferenciar as modalidades dos cursos de graduação através da flexibilização curricular, ensejando a constituição de cursos aligeirados, a implementação dos ciclos básicos e profissionais, a criação de bacharelados interdisciplinares, estimulou a mobilidade acadêmica através das instituições e criou política de $\mathrm{EaD}$ (MANCEBO, 2015; DE PAULA, 2016).

Cinquenta e três das cinquenta e quatro universidades federais brasileiras aderiram ao REUNI e além da flexibilização curricular, mediante a sua efetiva implantação e consolidação, a partir de 2008, ocorreu o aumento de 132.451 para 147.277 vagas para discentes, bem como, novos 
concursos para docentes e servidores foram realizados, culminando em 1.560 posses nas instituições federais de ensino superior (DE PAULA, 2016). Logo:

Com o aumento nas vagas discentes nas IFES através do REUNI, o governo Lula da Silva não se circunscreveu apenas nesse aspecto, pois novas universidades federais foram criadas [...] passando de 53, em 2007, para 59 em 2010. Conforme dados divulgados pelo MEC em 2010, no governo Lula da Silva 13 universidades federais foram criadas, além de cerca de 100 novos campi universitários, caracterizando, assim, o governo Lula da Silva como o governo que mais criou universidades públicas federais no Brasil (ALMEIDA, 2017, p. 120).

É preciso também dizer que o governo Lula além da preocupação com a ociosidade do setor da educação superior do âmbito federal entendia que a ampliação de vagas nas instituições federais de ensino superior seria por meio de cursos noturnos como ação mais adequada para acesso e permanência no nível superior. Assim, duas grandes frentes foram estabelecidas para facilitar o acesso à educação superior: a) a criação de formas democráticas e alternativas de ingresso ao vestibular e b) a instituição de políticas afirmativas (CARVALHO, 2015).

Em relação ao governo Dilma Rousseff (2011-2016), foram criadas na gestão da presidenta mais quatro universidades federais (logo, no governo do Partido dos Trabalhadores, ao todo, foram instituídas dezessete novas universidades federais). Mas apesar de intensificar as ações referentes ao REUNI, o Governo Dilma investiu e apostou de forma contundente na Rede Básica Federal de Educação Técnica, Profissional e Tecnológica (ALMEIDA, 2017). Os institutos federais tornaramse outro mecanismo de expansão da educação superior, visto que Lei $n^{0} 11.892 / 2008$ - instrumento de criação - especifica que os IFETs devem oferecer cursos de ensino superior, em especial licenciaturas, promover pesquisa (básica e aplicada) e extensão.

No entanto, o grande evento do governo Dilma foi a discussão do Plano Nacional de Educação (PNE 2014-2024), desta forma, a presidenta convocou os educadores para construir caminhos, diretrizes e metas no sentido de formular uma política nacional para a educação no Brasil, o eixo referencial desse contexto foi o debate democrático. No que diz respeito a educação superior, o PNE apresenta linhas de ação para dar continuidade a expansão do nível superior, tais orientações estão plasmadas na meta 12 e no subitem 12.2 do documento. Em relação a meta 12 :

Meta 12: elevar a taxa bruta de matrícula na educação superior para 50\% (cinquenta por cento) e a taxa líquida para $33 \%$ (trinta e três por cento) da população de 18 (dezoito) a 24 (vinte e quatro) anos, assegurada a qualidade da oferta e expansão para, pelo menos, $40 \%$ (quarenta por cento) das novas matrículas, no segmento público (BRASIL, 2014).

A meta 12 do PNE (2014-2024), ao aludir sobre a elevação da taxa líquida de matrículas discente para $33 \%$, está alinhada aos objetivos do REUNI. Já no item 12.2 pode-se ler:

12.2) ampliar a oferta de vagas, por meio da expansão e interiorização da rede federal de educação superior, da Rede Federal de Educação Profissional, Científica e Tecnológica e do sistema Universidade Aberta do Brasil, considerando a densidade populacional, a oferta de 
vagas públicas em relação à população na idade de referência e observadas as características regionais das micro e mesorregiões definidas pela Fundação Instituto Brasileiro de Geografia e Estatística - IBGE, uniformizando a expansão no território nacional (BRASIL, 2014).

Observa-se deste modo, o escopo da gestão Dilma em dar continuidade ao processo de expansão da rede federal de educação superior no Brasil iniciada no governo Lula através da criação de novas universidades, da UAB e dos institutos federais. No entanto, para Almeida (2017), apesar do sentido de continuidade, no governo da presidenta Dilma o PNE dá um caráter inovador ao processo de expansão da educação superior em território nacional, pois o REUNI ultrapassou os limites da esfera federal e passou a ser implementado, a partir dos critérios da meta 12, nas instituições de ensino superior estaduais e municipais, assim, o que era política de governo transformou-se em política de Estado.

Ademais, é importante destacar outras ações estatais promovidas durante os governos do Partido dos Trabalhadores. Neste período, o MEC adotou o Exame Nacional de Ensino Médio (ENEM) como o modelo alternativo de acesso a universidades públicas e que adquiriu papel central as universidades privadas durante o governo Lula a partir da criação do PROUNI, sobretudo, para ter direito a bolsa o exame passou a ser obrigatório. Pensando na unificação do processo e na democratização do acesso à Universidade, em 2010, foi criado o Sistema de Seleção Unificada (SISU), um sistema informatizado que oferece as vagas públicas da universidade para candidatos que participam do ENEM. A título de exemplo, o SISU como incremento ao ENEM como política de acesso, durante o primeiro mandato da presidenta Dilma acresceu em 55\% o número de inscrições no exame.

Outro ponto de destaque foi o sancionamento da Lei $\mathrm{n}^{\mathrm{o}} 12.711 / 2012$ que determinou a reserva de $50 \%$ das vagas de cursos de graduação, destinadas a estudantes que cursaram de forma integral o ensino médio em escolas públicas e sendo que destes, outros $50 \%$ contemplam estudantes oriundos de famílias de baixa renda. Além de vagas específicas para aos autodeclarados pretos, pardos e indígenas. Uma política afirmativa que se destina a atender às demandas das camadas historicamente excluídas do ponto de vista econômico e social.

Ainda é preciso dizer que as ações conduzidas durante os governos Lula e Dilma referentes a expansão da rede pública de educação superior possibilitaram uma expressiva ampliação da pósgraduação no Brasil, se os cursos de graduação presencial foram ampliados em 86\% em comparação aos anos FHC, a pós-graduação apresentou um crescimento de 316\%. O processo de expansão promoveu ampliação da rede federal de ensino superior e de campus no interior do território brasileiro, o que consequentemente promoveu a expansão das vagas públicas, diferenciando-se do tradicional modelo de oferta de vagas nas capitais e elevou o número de municípios atendidos pelas universidades federais de 114 para 289 (ALMEIDA, 2017). 
No entanto, todo esse processo de expansão do ensino superior vem sofrendo ataques que possuem como objetivo o sucateamento e até o fechamento de cursos e unidades educacionais; esses ataques ocorrem de forma direta por meio de cortes de verbas e de maneira indireta por meio de políticas de controle e que afetam diretamente a autonomia das universidades.

\section{OS CORTES DE VERBAS NAS INSTITUIÇÕES PÚBLICAS DE ENSINO: O DESMONTE DO ENSINO SUPERIOR}

Após esse cenário de expansão do ensino superior no Brasil, aumento de ações afirmativas que foram desenvolvidos no governo Lula e continuado pelo governo Dilma, exigem investimento para que sejam mantidos com qualidade, ou seja, é necessário a manutenção do projeto, mas com a mudança do bloco do poder no governo o projeto foi alterado e todas as conquistas passaram a ser atacadas.

Cabe ressaltar que a partir disso, houve uma busca de reestruturação do capitalismo no país. Rosa e Martins (2018) afirmam que essa reestruturação do capitalismo brasileiro se iniciou ainda durante o movimento de golpe parlamentar-judicial-midiático da então presidenta da república Dilma Rousseff e se concretizou com a posse ilegítima do Temer.

Ao tempo em que se fortalecia a volta da direita no cenário político, começaram os ataques e desmontes às universidades públicas no país. Tratando sobre esse desmonte, Stefani, Aguiar e Honório (2019, p.9) afirmam que somente "entre 2014 e 2018 diminuiu de R\$ 11,3 bilhões para $\mathrm{R} \$ 4,9$ bilhões" os investimentos com a educação superior.

(...) o que podemos presenciar é uma mudança radical nas ações governamentais, buscando ajustes econômicos e colocando em risco os direitos sociais conquistados. Na educação superior é clara a tendência a privatização, com a influência do Banco Mundial, de uma forma ainda mais contundente do que a praticada pelos governos petistas. Observamos um processo de desmonte da rede federal, que foi fomentada pelos governos anteriores. A atuação do governo reflete no corte de verbas para manutenção da expansão que as IES haviam tido nos anos anteriores, enxugamentos da contratação de pessoal via concursos públicos. Por falta de verbas acaba-se reduzindo a atividade universitária ao ensino, deixando de lado o investimento em pesquisa e extensão que são fundamentais para a vida da universidade. Para atender ao mercado, se intensifica a oferta de cursos aligeirados e a expansão da EaD. (ROSA; MARTINS, 2018, p.7-8).

Estes cortes de verbas na educação, tratados pelo governo de contingenciamento de gastos, representaram e representam um ataque aos direitos trabalhistas e visa uma precarização do trabalho e foi através da Emenda Constitucional que tramitou na Câmara, PEC n²41, depois no Senado PEC $\mathrm{n}^{\mathrm{o}} 55$ que esse desmonte se concretizou, pois, prevê o congelamento dos investimentos nessa área por 20 anos.

Um ataque claro aos direitos dos trabalhadores e por consequência a educação pública, que também se corporificou através da Medida Provisória (MP) 792, que constituiu um Programa de Demissão Voluntária (PDV) nada mais, nada menos que uma armadilha para os servidores 
públicos. Ainda prevê a redução de carga horária, combinada com a redução de salário, além de facilitação de licença sem remuneração, dando autonomia para gestores das instituições públicas decidirem sobre a licença e redução de carga horária. No entanto, devido organização do funcionalismo e muitos protestos a MP 792 teve seu prazo de vigência encerrado em 28 de novembro de 2017. (ROSA; MARTINS, 2018, p. 9).

Para entender melhor esse ataque é importante analisar os orçamentos aprovados para as universidades federais de 2011 a 2021 como pode ser visualizado através da figura 1 produzido pela Sindicato dos Trabalhadores do Judiciário Federal no Rio Grande do Sul (2021), demostrando o quão grande foi a diminuição dos valores investidos nas universidades federais a partir do ano de 2018.

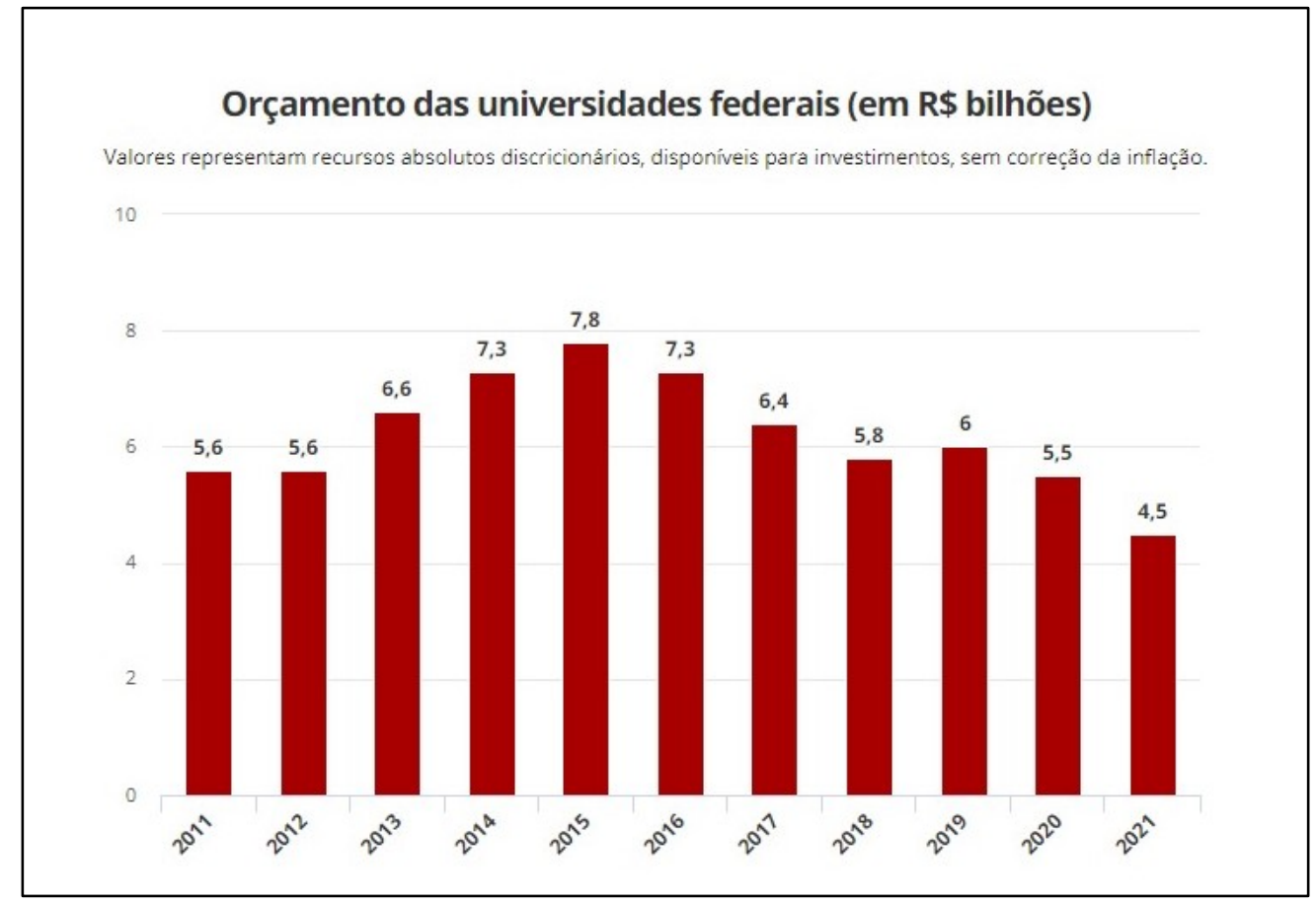

Figura 1 - Redução nas verbas destinadas às instituições de ensino superior 2011-2021. Fonte: SINTRAJUFE, 2021.

Segundo o site oficial da APUB (Associação dos Professores Universitários da Bahia), o orçamento “em 2020, passou para R \$ 5,54 bilhões e, em 2021, o valor aprovado na Proposta de Lei Orçamentária Anual (PLOA) foi de R\$ 4,49 bilhões - ou seja, menos 18,2\% (R\$ 1,056 bilhão) em relação ao ano anterior".

Esses cortes refletem, por exemplo, na possibilidade de contratação de novos professores e de Técnicos em Assunto Educacionais (TAEs), nos serviços básicos na universidade como na limpeza, materiais de higiene, entre outros. Além disso há também, muitas vezes, uma redução dos funcionários que prestam serviços terceirizados nessas instituições, ampliando o número de demissão.

Segundo Almeida (2021, p.1) estes cortes ameaçam também "a permanência de muitos de nossos pesquisadores, que se têm deslocado para o exterior à procura de mais investimentos em suas pesquisas". 
A Portaria 34, publicada no Diário Oficial da União na quarta-feira (18), altera novamente os critérios de distribuição das bolsas de mestrado e doutorado, modificando os pisos e tetos de cortes das bolsas. Com isso, retira bolsas de programas, principalmente os de notas 3, 4, 5, remanejando-as para programas de maiores conceitos. Embora a Capes insista que o novo cálculo não representa corte de bolsas, diversas universidades já se manifestaram sobre o impacto que a mudança terá em seus programas de pós-graduação (...) somente em 2019, mais de 12 mil bolsas de mestrado e doutorado foram extintas. No ano passado, o governo Bolsonaro cortou $87 \%$ do orçamento do CNPq e $50 \%$ do orçamento da Capes previstos para 2020. (ANDES, 2021).

Esses cortes foram responsáveis pela redução da assistência estudantil, diminuindo por exemplo, os auxílios-moradia, auxílios-alimentação, transporte, creche, entre outros tantos que garantem o acesso e a permanência desses alunos na instituição de ensino que os mesmos ingressaram. Segundo a Andes (2019);

(...) o orçamento da educação federal já era insuficiente, pois diversas reduções também foram realizadas na área em anos anteriores. Agora, com a situação agravada, muitos efeitos já são sentidos pelas comunidades acadêmicas. Os programas de assistência e permanência estudantil estão entre os elos mais fracos da educação federal. Voltados para garantir o acesso e a permanência de estudantes de baixa renda nas instituições de ensino, muitos programas já têm sofrido corte (ANDES,2019).

Essa falta de garantia, muitas vezes desmotiva e impede que os alunos e alunas da classe trabalhadora possam finalizar seus cursos, pois, muitos deles não conseguem se manter nas respectivas cidades onde estudam, ou não conseguem divulgar os resultados de suas pesquisas em congressos e em eventos científicos. Lançar-se no mercado de trabalho se torna uma das únicas opções para esses estudantes, que nem sempre conseguem conciliar estudo e trabalho e desistem do segundo, priorizando manter-se em seus empregos, pois a sobrevivência é imediata.

Ao mesmo tempo que houve essa ofensiva nas instituições de ensino público, notou-se que há um incentivo para o ingresso nas universidades na modalidade a distância no país. Como pode ser visto através da figura 2, elaborados pelo Inep (2020), nos anos de 2018 e 2019 as vagas oferecidas nesses cursos EAD tiveram um aumento consideravelmente grande.

Não se garante a permanência dos alunos nas universidades públicas, porém, incentivam através de políticas governamentais o acesso a instituições de ensino privado, sejam essas instituições de ensino presenciais ou em EAD, com oferta de financiamento/bolsas advindas do poder público. Esse fato pode ser percebido pelo crescente número de matrículas na rede privada a partir do ano do golpe político, como pode ser visto na figura 3.

Segundo os dados do INEP (2020) no ano de 2019 eram 302 instituições de ensino superior públicas em atividade no país, enquanto as privadas somavam-se 2.306 instituições. No ano de 2019, mesmo com os desmanches das instituições em andamento, houve ainda 559.293 ingressantes nos mais variados cursos e concluintes foram cerca de 251.374 estudantes, equivalendo a cerca de $44,94 \%$ 
do total de inscritos. Desse modo, havia uma média de 1.851 estudantes por instituição e cerca 832 alunos de cada instituição conseguiram finalizar seus respectivos cursos.

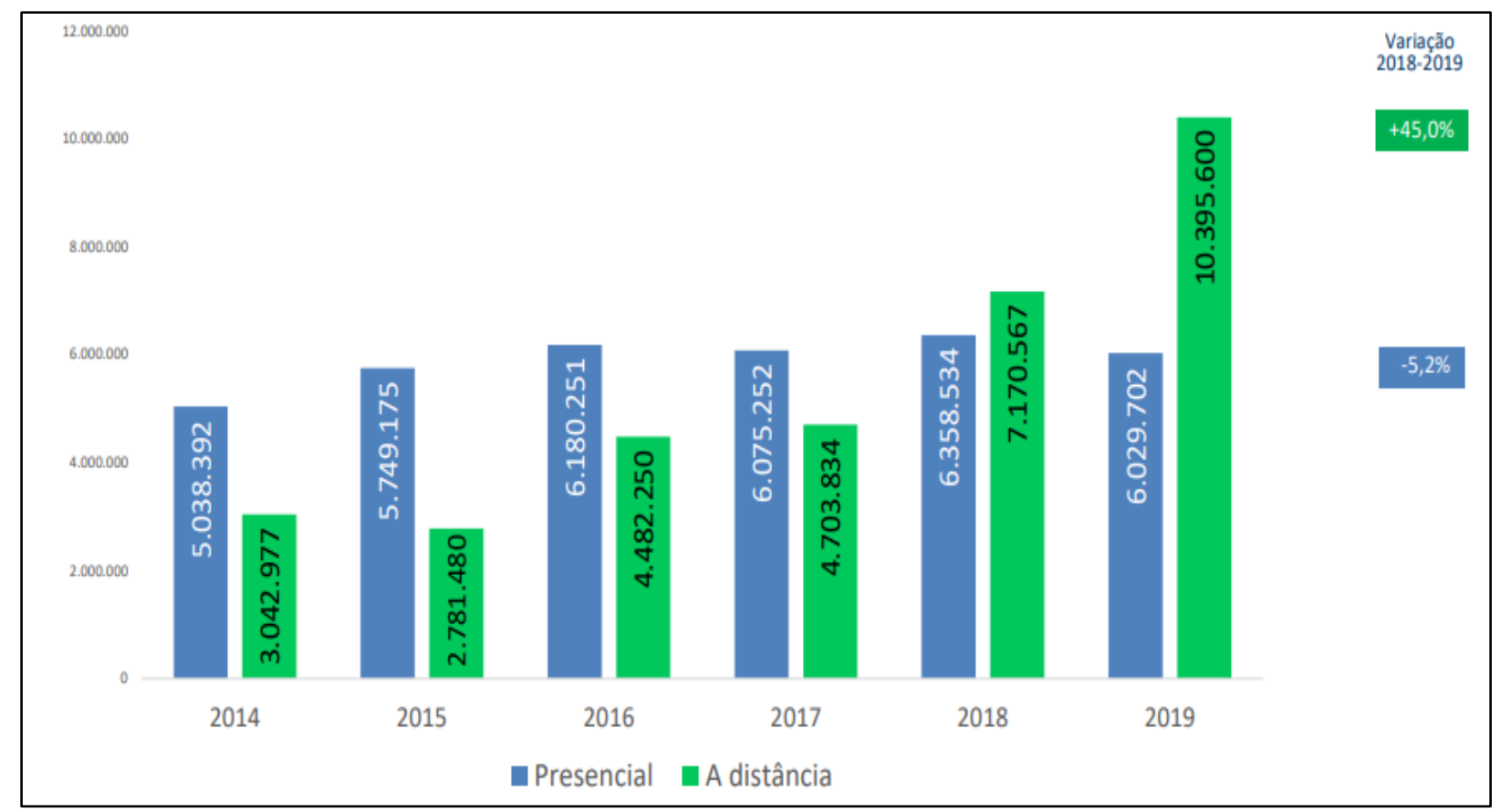

Figura 2 - Número de vagas oferecidas em cursos de graduação, por modalidade de ensino Brasil (2014-2019). Fonte: MEC/Inep. Censo da Educação superior (2020).

No mesmo ano, nas instituições privadas, houve o ingresso de 3.074.027 estudantes e apenas 998.702 concluíram os cursos que iniciaram, equivalendo a 32,48\% do total. Pensando em valores médios, eram 1.333 estudantes por instituição de ensino, e cerca de 433 apenas conseguiram finalizar seus cursos.

Portanto, quando um governo ataca as instituições de ensino superior através dos cortes orçamentários, promovendo a precarização dessas instituições, a incerteza do acesso e permanência dos alunos, promovendo uma necessidade de produção em larga escala e imediatistas para acesso a bolsas e financiamentos e por meio de editais específicos, ele está demostrando sua face mais perversa, a de um Estado que tem sua origem burguesa e de viés elitista. Nesse sentido, a educação se torna uma mercadoria a ser vendida, tendo acesso a ela, somente aqueles das classes mais abastadas.

Mas os ataques não são realizados somente por meio de cortes de verbas, mas ocorrem também por meio de políticas que controlam e afetam a autonomia universitária. 


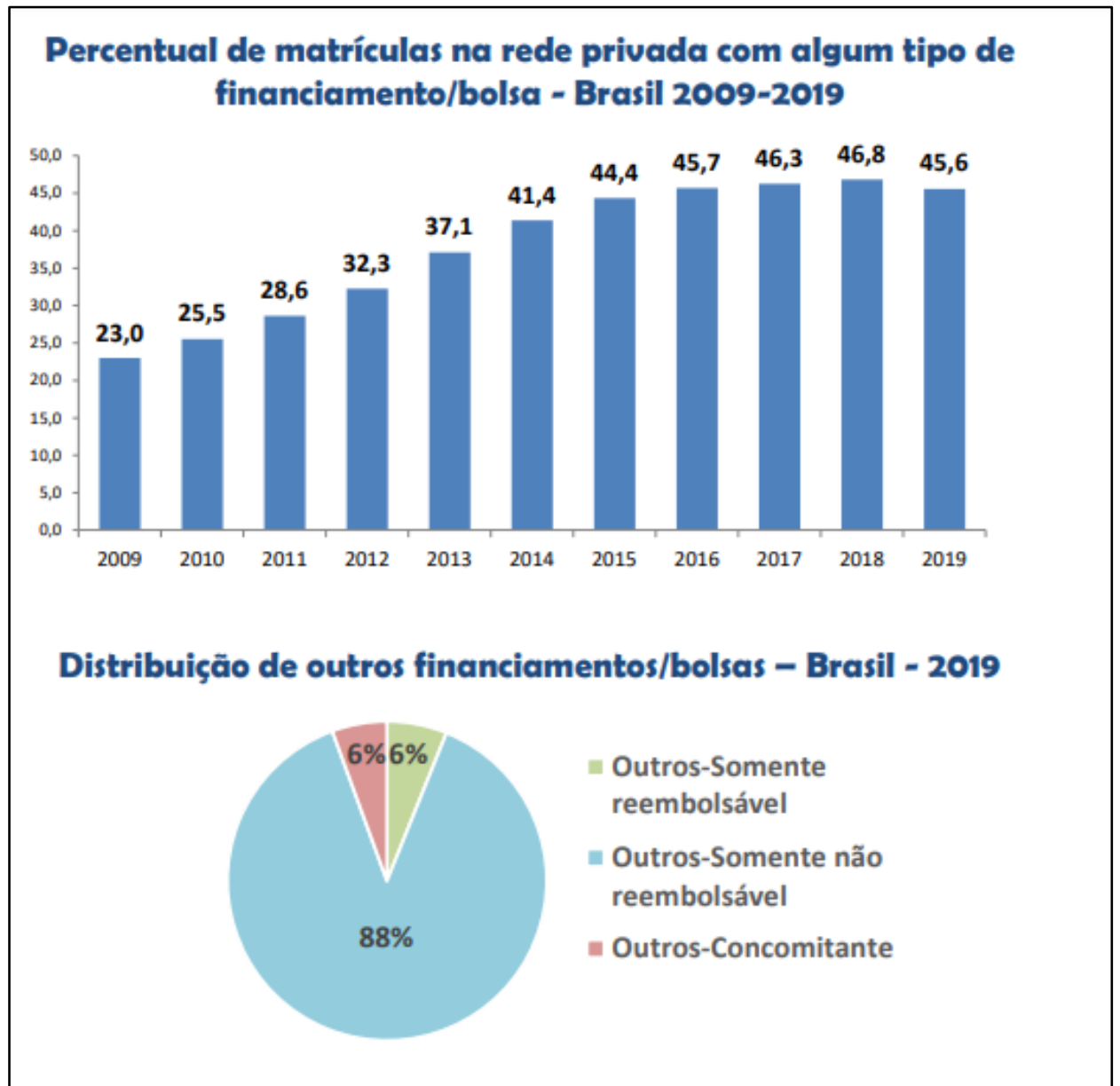

Figura 3 - Matrículas na rede privada e relação com financiamentos/bolsas (2009-2019). Fonte: MEC/Inep. Censo da Educação Superior (2020).

\section{AS POLÍTICAS EDUCACIONAIS DOS CURSOS DE FORMAÇÃO DE PROFESSORES E A INTERVENÇÃO NA AUTONOMIA DA UNIVERSIDADE}

Os cursos de formação de professores sempre foram marcados por normativas legais. Saviani (2009) ao analisar esse processo histórico destacou os seguintes marcos: O dispositivo da Lei das Escolas de Primeiras Letras (1827-1890), a Reforma Paulista da Escola Normal (1890-1932), a Organização dos Institutos de Educação (1932- 1939), a Organização e implantação dos Cursos de Pedagogia e de Licenciatura e consolidação do modelo das Escolas Normais (1939-1971), a substituição da Escola Normal pela Habilitação Específica de Magistério (1971-1996) e advento dos Institutos Superiores de Educação, Escolas Normais Superiores e o novo perfil do Curso de Pedagogia (1996-2006).

Todos esses processos históricos apresentados por Saviani (2009) indicam uma busca por uma adequada formação de professores, que superasse o formato denominado de " $3+1$ ". Porém, segundo Sheibe (1983, p. 43), esse esquema tradicional ainda permanece “(...) sobre uma base substancial de conteúdo específico, acrescenta-se uma "complementação pedagógica" e a desintegração entre estas duas áreas continua a existir”. 
As pesquisas sobre formação de professores confirmam que é necessária uma melhor articulação dos conteúdos específicos com os conteúdos pedagógicos na formação de professores, pois, o professor precisa dominar o conteúdo específico que vai desenvolver com o aluno, mas, também precisa dominar conteúdos pedagógicos que vão conduzir sua prática em sala de aula, buscando a superação da transmissão pela mediação de conteúdo.

A legislação é um potente instrumento para possibilitar transformações que podem ser positivas quando o documento legal em questão é construído pautado em reivindicações da população que será regida por eles e negativo quando é produzido por pessoas que não dialogam ou que não conhecem a real vivência do público que será afetado diretamente por este documento.

No caso da formação de professores é possível afirmar que três resoluções abriram possibilidades de melhorias nos cursos de formação são elas: a Resolução CNE/CP 1, de 18 de fevereiro de 2002 que instituiu Diretrizes Curriculares Nacionais para a Formação de Professores da Educação Básica, em Nível Superior, Curso de Licenciatura, de Graduação Plena juntamente a Resolução CNE/CP 2, de 19 de fevereiro de 2002 que instituiu a duração e a carga horária dos cursos de licenciatura, de graduação plena, de formação de professores da Educação Básica em nível Superior e a Resolução No2, de $1^{\circ}$ de Julho de 2015 que definiu as Diretrizes Curriculares Nacionais para a Formação Inicial em Nível Superior (cursos De Licenciatura, Cursos de Formação Pedagógica para Graduados e Cursos de Segunda Licenciatura) e para A Formação Continuada.

Apesar de apresentar em seu documento uma organização pautada em competências as diretrizes de 2002 podem ser consideradas como normativa positiva, pois, segundo Schneider (2007, p.13) "Por não oferecerem caminhos fechados, elas são consideradas um avanço em relação a propostas anteriores, consubstanciadas pela acepção de Estado Autoritário, que fixava currículos mínimos". Como ponto positivo destas resoluções de 2002, destaca-se também, a inserção de 400 horas de Prática como Componente Curricular presente desde o início do curso, 400 horas dedicadas ao estágio supervisionado a partir da metade do curso, e a obrigatoriedade das dimensões pedagógicas ocuparem quinta parte da carga horária total do curso.

As diretrizes de 2015 apresentam um expressivo avanço, pois, articulam a formação inicial com a formação continuada, afinal a formação de professores para ser realizada de forma adequada pressupõe uma relação entre os cursos de formação de professores e os professores que estão atuando na educação básica. Outro ponto de destaque desta diretriz é o capítulo VII- Dos profissionais do magistério e sua valorização, pois, a melhoria na formação de professores está articulada ao processo de valorização dessa profissão. Ainda sobre esse documento Dourado (2015, p. 309) afirma que,

Visando garantir diretrizes nacionais articuladas à trajetória das instituições formadoras, as novas DCNs definem que os cursos de formação inicial, respeitadas a diversidade nacional e a autonomia pedagógica das instituições, constituir-se-ão dos seguintes núcleos: 
I. Núcleo de estudos de formação geral, das áreas específicas e interdisciplinares, e do campo educacional, seus fundamentos e metodologias, e das diversas realidades educacionais;

II. Núcleo de aprofundamento e diversificação de estudos das áreas de atuação profissional, incluindo os conteúdos específicos e pedagógicos e a pesquisa priorizadas pelo projeto pedagógico das instituições, em sintonia com os sistemas de ensino; e

III. Núcleo de estudos integradores para enriquecimento curricular.

Ou seja, apesar de ser uma normativa ela não engessa os projetos pedagógicos dos cursos de formação de professores e não afeta de forma negativa a autonomia da universidade. As diretrizes de 2015 podem ser entendidas como continuidade e avanço das diretrizes de 2002 pois muitos dos seus pontos foram mantidos e ampliados. Na última resolução destaca-se a importância dos conteúdos relacionados a diversidade na educação e a gestão educacional. Em seu artigo 13,

$\S 2^{\circ}$ Os cursos de formação deverão garantir nos currículos conteúdos específicos da respectiva área de conhecimento ou interdisciplinares, seus fundamentos e metodologias, bem como conteúdos relacionados aos fundamentos da educação, formação na área de políticas públicas e gestão da educação, seus fundamentos e metodologias, direitos humanos, diversidades étnico-racial, de gênero, sexual, religiosa, de faixa geracional, Língua Brasileira de Sinais (Libras), educação especial e direitos educacionais de adolescentes e jovens em cumprimento de medidas socioeducativas. (BRASIL, 2015).

Pautada nessas diretrizes a Universidade Federal de Alfenas, em Minas Gerais, que possuía 13 cursos de licenciaturas, por meio de sua Pró-Reitoria de Graduação, assessorada pelo Núcleo das Licenciaturas, conseguiu ampliar seu quadro de professores com a contratação de professores para os cursos de licenciaturas sendo um para a disciplina de Gestão Educacional e outro para a disciplina Educação e Relações Étnico-Raciais no ano de 2017. O exemplo do que aconteceu nesta instituição é importante para demostrar que quando as políticas educacionais dialogam com o movimento que busca sempre fortalecer a formação de professores, e encontram gestores de instituições de cursos superiores que buscam implementar as normas de forma a atender a realidade e possuem apoio e investimentos do governo federal, os ganhos podem ser significativos. Apesar dessa conquista de dois novos profissionais para atuarem especificamente nos cursos de licenciaturas, ainda foram mantidos outros desafios, os quais passam a ser ampliados com a aprovação das novas diretrizes em 2019.

Como uma ruptura do movimento apresentado nas normativas de 2002 e 2015 foi aprovada a Resolução CNE/CP N 2, de 20 de dezembro de 2019 que define as Diretrizes Curriculares Nacionais para a Formação Inicial de Professores para a Educação Básica e institui a Base Nacional Comum para a Formação Inicial de Professores da Educação Básica (BNC-Formação), elaborada e aprovada sem diálogo com os pesquisadores e associações que envolvem a temática, com um conteúdo que fere a autonomia universitária e amarra a formação de professores à Base Nacional Comum Curricular da educação básica. Essa normativa possui uma ampla rejeição. 
A Associação Nacional de Pós-Graduação e Pesquisa em Educação (ANPEd) se posicionou sobre "Texto Referência - Diretrizes Curriculares Nacionais E Base Nacional Comum para a Formação Inicial e Continuada de Professores da Educação Básica",

(...) reafirma-se a posição da ANPEd, manifesta neste egrégio Conselho por ocasião da audiência pública realizada em 06 de maio de 2019, de que a Resolução CNE/CP n ${ }^{\circ}$ 2/2015 expressa a concepção e os princípios da ideia de base comum nacional para a formação de professores edificada pelo movimento dos educadores. Nesse sentido, ela registra, de um lado, conquistas para a formação dos profissionais ao consolidar normas e diretrizes nacionais em sintonia com a defesa da escola pública de qualidade; e de outro, sua suficiência, indicando que a aprovação da BNCC não demanda mudanças nas DCNs de formação de professores, (...) (ANPEd, 2019).

Essa associação deixa claro que as diretrizes de 2015 representam um movimento dos educadores, e que a aprovação da BNCC não justifica a revogação da mesma. Na verdade, esse elemento é um fator essencial para a manutenção desta diretriz, pois, atende os anseios dos sujeitos envolvidos. O caminho deveria ser o contrário, no sentido de fortalecer a implementação do que é proposto no documento e apoiar as instituições que ainda não conseguiram realizar a adaptação de seus Projetos Pedagógicos de Cursos à DCN de 2015.

No caso do curso de Geografia da Universidade Federal de Alfenas, as mudanças foram efetivadas em 2018, ou seja, a primeira turma a formar com as modificações propostas pelas diretrizes de 2015 será em 2022, ou seja, grande parte das instituições não conseguiram formar turmas para poder fazer uma avaliação do resultado das mudanças e organizar possíveis adaptações, o que torna ainda mais desrespeitosa a aprovação de uma nova resolução em 2019. Pautada também nesse argumento a Sociedade Brasileira para o Progresso da Ciência se manifestou com preocupação a BNC-Formação e enfatizou que o momento exige prudência, cautela e sensibilidade, em carta endereçada ao Conselho Nacional de Educação afirma que,

muitas instituições de educação superior (IES) recém realizaram alterações profundas em seus currículos para o conjunto dos cursos de licenciatura que ofertam, seguindo o Parecer CNE/CP $\mathrm{n}^{\circ} 2$, de 9 de junho de 2015 e a Resolução CNE/CP n ${ }^{\circ} 2$ de 1 de julho de 2015; que estes novos currículos ainda estão em fase inicial de avaliação institucional; e que alguns dos seus componentes curriculares sequer foram ainda validados; (SBPC, 2021).

\section{A Associação Nacional de Pós-Graduação e Pesquisa em Geografia também se posicionou}

contra a BNC-Formação, pois entende que a mesma está inserida em projeto de controle e mercantilização da educação básica, do ensino superior e da formação continuada, desta forma afirma que,

Para o mercado, tais regulações e controles são fundamentais, pois propiciam a homogeneização do sistema nacional de ensino, condição para a oferta de produtos e serviços educacionais. Importante destacar que, no que se refere à formação continuada, o Conselho Nacional de Educação (CNE) elaborou Parecer e Resolução encaminhados ao Conselho Pleno instituindo as Diretrizes Curriculares Nacionais da Formação Continuada dos Profissionais da Educação Básica, sem consultar os diferentes profissionais da área e suas 
entidades representativas (docentes da educação básica e universitária, sindicatos, associações etc.). Em função disso é apresentado este documento, no entendimento de que a atual situação é de extrema gravidade, sobretudo por dois motivos: (1) trata-se de uma ameaça à autonomia universitária e (2) pode ser considerado como um desrespeito ao Decreto 8752/2016 que dispõe sobre a Política Nacional de Formação dos Profissionais da Educação básica, documento elaborado coletivamente por conjunto de especialistas ligados à formação de professores. Assim, considerando que uma diretriz não pode se contrapor a um decreto, denotando sua não conformidade legal. (ANPEGE, 2020, p.1 e 2).

A BNC-Formação impõe uma articulação do projeto pedagógico de curso à BNCC, impõe que as disciplinas de cunho pedagógico se concentre no início do curso e as disciplinas do conteúdo específico da área a partir do segundo ano, estabelecendo um 3+1 ao contrário, em vez de propor uma articulação que é indicada nas diretrizes de 2015, impõe a avaliação de práticas pedagógicas por meio de portfólio, ou seja, uma série de imposições que afetam diretamente a organização dos cursos de acordo com suas particularidades.

Outra questão importante de se ressaltar é que para articular a formação inicial à educação básica não é necessário uma imposição ao currículo da educação básica, mas sim criar condições para que o diálogo entre a escola e a universidade se amplie, como por exemplo, condições para o que o professor-orientador de estágio tenha uma relação de proximidade com o professor supervisor de estágio, e que este tenha o trabalho de supervisão reconhecido financeiramente, para que possam planejar em conjunto as 400horas de estágio. Outro elemento importante é criar condições de ingresso e de permanência dos alunos do curso de licenciatura para que esses possam vivenciar a universidade por meio do ensino, da pesquisa e da extensão, fato que na maioria das vezes é impossibilitado para o aluno trabalhador

Cabe salientar que 30 entidades nacionais assinaram uma nota em defesa da Resolução 02/2015, contra o que denominaram de "descaracterização da formação de professores". Entre as entidades, destacamos para além da ANPED, já citada anteriormente, a assinatura da Associação Nacional pela Formação dos Profissionais da Educação (ANFOPE), do Fórum Nacional de Diretores de Faculdades, Centros de Educação ou Equivalentes das Universidades Públicas Brasileiras (FORUMDIR), da Associação Brasileira de Currículo (ABdC), do Fórum Nacional dos Coordenadores Institucionais do PIBID e do Residência Pedagógica (FORPIBID-RP), da União Nacional dos Estudantes (UNE) e do FÓRUM NACIONAL POPULAR DE EDUCAÇÃO (FNPE). Assim, frente ao exposto, defendemos a revogação da BNC-Formação, nos somando às instituições democráticas citadas anteriormente, evidenciando que a autonomia escolar e universitária é um princípio fundamental para se pensar o currículo. (ANPEGE, 2020, p.9).

Diante dessa resistência das associações à BNC-Formação o governo federal resolveu lançar um edital de incentivo para a adequação a essa normativa, ou seja, é criada uma estratégia para forçar a aceitação, o governo reduz as verbas da universidade e oferece programas envolvendo verbas para convencer as instituições a aderirem a normativa devido sua necessidade financeira.

O edital no 35, de 21 de junho de 2021, que lançou o Programa Institucional de Fomento e Indução da Inovação da Formação Inicial Continuada de Professores e Diretores Escolares, explicita 
sua contribuição na implementação da BNC-Formação, dentre os seus objetivos consta, “2.3.2. b) promover a adequação da Pedagogia e das Licenciaturas à Base Nacional Comum Curricular (BNCC), aos currículos e às matrizes estabelecidas pelas redes de ensino, às propostas pedagógicas curriculares das escolas de Educação Básica e à BNC-Formação Inicial;” (BRASIL, 2021)”. No item 4 onde define os projetos que podem ser submetidos ao edital explicita que:

4.4. Os projetos submetidos a este Edital devem incidir: na articulação entre teoria e prática; no alinhamento de Propostas Pedagógicas da Pedagogia e Licenciaturas às novas Diretrizes Curriculares Nacionais (DCNs), à Base Nacional Comum Curricular (BNCC) e à Base Nacional Comum para a Formação Inicial de Professores da Educação Básica (BNCFormação); na promoção de propostas formativas inovadoras que contemplem o uso pedagógico de tecnologias, metodologias ativas, ensino híbrido e empreendedorismo; e na articulação entre universidades e redes de ensino. (BRASIL, 2021).

Além de obrigar os projetos a estarem alinhados as BNCC e a BNC-Formação, ainda impõe a presença de metodologias ativas e de empreendedorismos. Sobre esses aspectos Leal e Sales (2018) em sua pesquisa sobre as metodologias ativas e curso de formação de professores afirmam que,

Foi possível observar que as metodologias consideradas ativas são validadas por docentes universitárias/os e adquirem estatuto de verdade de inovação pedagógica na docência do ensino superior. Tal validação constitui-se em um efeito da ordem discursiva vigente da "sociedade da inovação", que, por sua vez, produz as posições docentis innovatus e discipulus iacto. O uso das metodologias ativas, portanto, faz parte de um discurso autorizado sobre inovação na docência universitária, que é articulado ao dispositivo de inovação na fabricação dessas posições de sujeito. É interessante para lógica do mercado, neste contexto político, histórico e social, em que se constitui a "sociedade da inovação", formar sujeitos ativos, empreendedores de si e competitivos para o funcionamento da concorrência incitada pela racionalidade neoliberal, em cuja centralidade está a liberdade de mercado. As metodologias ativas, engendradas nessas relações de poder, são posicionadas como "verdade" na produção da inovação no ensino, porque elas produzem o tipo de sujeito de que o mercado necessita (LEAL e SALES, 2018, p.15).

Ou seja, a universidade que deveria se posicionar contra uma educação meritocrática e individualista, passa a se organizar, e muitas vezes estimuladas pelo governo como é o caso do edital estudado, pautadas em metodologias ativas reforçando uma educação para atender o mercado e os princípios neoliberais.

No mesmo documento no item 5.1. Das Instituições Proponentes, o documento deixa claro que a proposta tem que estar atrelada a BNCC e a BNC-Formação,

5.1.1. Poderão submeter proposta para a oferta de vagas em cursos de Pedagogia e Licenciaturas, nos termos do Anexo I, as IES públicas ou privadas sem fins lucrativos que atendam aos seguintes requisitos:

I - Apresentar Proposta Institucional que comprove:

a) alinhamento das Propostas Institucionais da Pedagogia e das Licenciaturas à BNCC, às novas DCNs e à BNC-Formação; (BRASIL, 2021).

Esse último item explicita a articulação dos documentos legais que visam controlar todas as etapas e níveis da educação brasileira, ou seja, desde a educação infantil até o ensino superior dentro 
de uma proposta de educação pautada em competências e habilidades e que limita a pluralidade de ideias e de modelos.

Mesmo diante de um cenário de cortes de verbas e desmonte das universidades públicas, houve manifestações contrárias a este edital, ressaltando que o dinheiro não está acima de um projeto de educação, pública, gratuita e de qualidade, e que o dinheiro deveria ser para fortalecer esse projeto de educação. Um exemplo dessas manifestações foi a nota de repúdio do Fórum Nacional de Diretores e Diretoras de Faculdades/Centros de Educação ou Equivalentes das Universidades Públicas Brasileiras (ForumDir) que se manifestou veementemente contra o Programa Institucional de Fomento e Indução da Inovação da Formação Inicial Continuada de Professores e Diretores Escolares e contra o Edital n 35 , de 21 de junho de 2021, dentre os motivos, destaca-se que:

O Edital no 35/2021 é totalmente adverso e, portanto, inviável pois, se constitui em mais uma manobra política de investida para insertar a educação ao ideário do campo empresarial, subordinados ao modelo economicista, cujas palavras de ordem são a produtividade, eficiência, eficácia, meritocracia, empreendedorismo da educação e de seus sistemas de ensino. (FORUMDIR, 2021).

Apesar de todo o avanço neoliberal na educação por meio das políticas educacionais, permanece forte e resistente a busca por uma educação transformadora, que busca um processo de emancipação para seus sujeitos e que enfrenta as políticas pautadas em pedagogia das competências.

\section{CONSIDERAÇÕES FINAIS}

Através dos debates realizados percebeu-se que o atual governo teme a capacidade democrática, formativa e organizacional das universidades públicas do país, pois boa parte daqueles que a compõe se opõem aos desmandos, autoritarismo e anti-democracia propostos pelo projeto político do bloco de poder que está no governo. Além disso, a garantia de uma educação de qualidade, que seja crítica e motive a reflexão, não é uma das prioridades dessa agenda governamental, ao contrário, são registradas cada vez mais denúncias de repressão à algumas temáticas pesquisadas.

Entende-se que uma sociedade que não é incentivada a expandir seus conhecimentos e ter autonomia e discernimento político e social de suas escolhas se tornam fáceis de serem manipuladas, conduzidas por quaisquer que sejam os caminhos sem que haja questionamentos sobre isso, ou até mesmo, vejam num discurso bruto e violento a saída para minimização das desigualdades vividas em seu país, sem a compreensão da totalidade e da responsabilidade política do Estado sobre tais desigualdades.

As Instituições de Ensino Superior possuem a responsabilidade social de realizar uma reflexão mais profunda sobre o contexto político, social e cultural vivido. É necessário garantir o 
funcionamento destas instituições e projetar uma ampliação do acesso aos seus produtos e serviços a toda sociedade.

Para finalizar, acredita-se que é necessário se manter atento as novas investidas e ataques que o governo impõe sobre a universidade, buscando retirar a autonomia da mesma e seu posterior sucateamento.

\section{REFERÊNCIAS}

ALMEIDA, M. M. A geopolítica das universidades federais/nacionais no Brasil e na Argentina de 2003 a 2015. 2015. 253 f. Tese (Doutorado em Geografia) - Faculdade de Ciências Humanas, Universidade Federal de Dourados. Dourados, 2017.

ALMEIDA, S. R. G. Cortes de verbas na ciência. Jornal Folha de São Paulo. 2021. Disponível em: https:/www1.folha.uol.com.br/opiniao/2021/07/cortes-de-verbas-na-ciencia-ameacam-o-futuro-dopais.shtml>. Acesso em: 12 ago. 2021.

ANDES. Sindicato Nacional Dos Docentes Das Instituições De Ensino Superior. Disponível em: https:/www.andes.org.br/conteudos/noticia/cortes-de-orcamento-ja-sao-sentidos-em-universidadese-institutos-federais1 Acesso em: 12 ago. 2021.

ANPED - Associação Nacional de Pós-Graduação e Pesquisa em Educação. Uma Formação Formatada: Posição da ANPed sobre o "Texto Referência- Diretrizes Curriculares Nacionais e Base Nacional Comum para a Formação Inicial e Continuada de Professores da Educação Básica”. Disponível em: https:/www.anped.org.br/news/posicao-da-anped-sobre-texto-referencia-dcn-ebncc-para-formacao-inicial-e-continuada-de. Acesso em: 07 ago. 2021.

ANPEGE - ASSOCIAÇÃO NACIONAL DE PÓS-GRADUAÇÃO E PESQUISA EM GEOGRAFIA. Nota técnica BNC Formação e reformas curriculares dos cursos de licenciaturas em geografia. Disponível em: <http://www.anpege.ggf.br/documentos.php>. Acesso em: 09 ago. 2021.

APUB - SINDICATO DOS PROFESSORES DAS INSTITUIÇÕES DEFERAIS DE ENSINO SUPERIOR DA BAHIA. Cortes de investimentos nas universidades federais. Disponível em: http://apub.org.br/impacto-dos-cortes-de-investimentos-nasuniversidades-federais. Acesso em: 12 ago. 2021.

BRASIL. Resolução CNE/CP 1/2002, de 18 de fevereiro de 2002. Institui as Diretrizes Curriculares Nacionais para a formação de professores da educação básica, em nível superior, curso de licenciatura, de graduação plena. Documento aprovado em 18.02.2002, publicado no DOU em 09.04.2002. 2002. Disponível em: http://portal.mec.gov.br/cne/arquivos/pdf/CP012002.pdf. Acesso em: 09 jun. 2021.

BRASIL. Resolução CNE/CP 2/2002, de 19 de fevereiro de 2002. Institui a duração e a carga horária dos cursos de licenciatura, de graduação plena, de formação de professores da Educação Básica em nível superior. 2002a . Disponível em: http://portal.mec.gov.br/index.php. Acesso em: 09 jun. 2021.

BRASIL. Lei $\mathbf{n}^{\mathbf{0}}$ 11.096, de 13 de janeiro de 2005. Disponível em: http://www.planalto. gov.br/ccivil 03. Acesso em: 6 ago. 2021. 
BRASIL. Decreto $\mathbf{n}^{\mathbf{0}} \mathbf{6 . 0 9 6}$, de 24 de abril de 2007. Disponível em: http://www.planalto. gov.br/ccivil_03/_ato2007-2010/2007/decreto/d6096.htm>. Acesso em: 6 ago. 2021.

BRASIL. Lei $\mathbf{n}^{0}$ 11.892, de 29 de dezembro de 2008. Disponível em: http://www.planalto. gov.br/ccivil_03/_ato2007-2010/2008/lei/111892.htm. Acesso em: 11 ago. 2021.

BRASIL. Lei no 13.005, de 25 de junho de 2014, que aprova o Plano Nacional de Educação (PNE) e dá outras providências. Disponível em: http://www.proec.ufpr.br/download/extensao /2016/creditacao/PNE\%202014-2024.pdf. Acesso em: 11 ago. 2021.

BRASIL. Resolução CNE/CP n. 02/2015, de 1 de julho de 2015. Define as Diretrizes Curriculares Nacionais para a formação inicial em nível superior (cursos de licenciatura, cursos de formação pedagógica para graduados e cursos de segunda licenciatura) e para a formação continuada. Diário Oficial [da] República Federativa do Brasil, Brasília $1^{\circ}$ jul. 2015. Seção 1, n. 124, p. 8-12. Disponível em: http://portal.mec.gov.br/docman/agosto-2017. Acesso em: 09 jun. 2021.

BRASIL. Resolução CNE/CP n. 2/2019, de 20 de dezembro de 2019. Define as Diretrizes Curriculares Nacionais para a Formação Inicial de Professores para a Educação Básica e institui a Base Nacional Comum para a Formação Inicial de Professores da Educação Básica (BNC-Formação), 2019b. Disponível em: http://portal.mec.gov.br/index.php?option=com. Acesso em: 10 ago. 2021.

BRASIL. Censo da Educação Superior. 2020. Disponível em: https://download.inep.gov.br/ educacao_superior/censo_superior/documentos/2020/ApresentacaoCensodaEducacaoSuperior2019. pdf. Acesso em: 12 ago. 2021.

BRASIL. Secretaria De Educação Básica. Edital $\mathbf{N}^{0}$ 35, de 21 de junho de 2021. Programa Institucional de Fomento e Indução da Inovação da Formação Inicial Continuada de Professores e Diretores Escolares. DIÁRIO OFICIAL DA UNIÃO,22/06/2021, Edição:115, Seção: 3, Página: 79. Disponível em: https://www.In.Gov.Br/En/Web/Dou/-/Edital-N-35-De-21-De-Junho-De-2021327345162. Acesso em: 09 ago. 2021.

CARVALHO, C. Política de Expansão da Educação Superior nos Governos Democráticos Brasileiros (1995-2013). In: SOUSA, J. V. Expansão e Avaliação da Educação Superior Brasileira: formatos, desafios e novas configurações. Brasília: Fino Traço. 2013.

. A política pública de expansão para a educação superior entre 1995 e 2010 uma abordagem neoinstitucionalista histórica. Revista Brasileira de Educação, v. 20 n. 60, p. 51-76, 2015.

DE PAULA, A. A política de educação superior nos governos petistas: a inflexão da universidade ao capital. 2016. 174 f. Dissertação (Mestrado em Educação) - Universidade Federal do Ceará, Fortaleza, 2016.

DOURADO, L. F. Diretrizes Curriculares Nacionais para a formação inicial e continuada dos profissionais do magistério da Educação Básica: concepções e desafios. Educação \& Sociedade, v. 36, n. 131, p. 299-324, 2015.

FORUMDIR. FÓRUM NACIONAL DE DIRETORES E DIRETORAS DE FACULDADES / CENTROS DE EDUCAÇÃO OU EQUIVALENTES DAS UNIVERSIDADES PÚBLICAS BRASILEIRAS. Nota de repúdio. Contra a PORTARIA Nº 412, DE 17 DE JUNHO DE 2021 que institui Programa Institucional de Fomento e Indução da Inovação da Formação Inicial Continuada de Professores e Diretores Escolares e contra o EDITAL N ${ }^{\circ}$ 35, DE 21 DE JUNHO DE 2021. 
Disponível em: https://formacaoprofessordotcom.files.wordpress.com/2021/07/nota-de-repudio-con tra-a-portaria-no-412-atualizada.pdf. Acessado em: 10 ago. 2021.

LEAL, R. E. G.; SALES, S. R. Metodologias ativas: efeitos de verdade acerca da inovação no ensino dentro da racionalidade neoliberal. Eccos - Revista Científica, São Paulo, n. 57, p. 1-19, 2021.

MANCEBO, D. Políticas de educação superior no Brasil. In: JÚNIOR, J. R. S.; SOUSA, J. V.; AZEVEDO, M. L. N.; LÚCIA, V.; CHAVES, J. Educação Superior: Internacionalização, mercantilização e repercussões em um campo de disputas. Belo Horizonte: Fino Traço, 2015.

RIBEIRO, C.; LEDA, D. O trabalho docente em uma Universidade Federal frente à interiorização da Educação Superior. In: SOUSA, J. S. Expansão e Avaliação da Educação Superior Brasileira: formatos, desafios e novas configurações. Brasília: Fino Traço, 2015.

ROSA, C. C. B. B.; MARTINS, S. A. Ensino Superior no Brasil: Uma Breve trajetória pós-golpe de 2016. Disponível em: https://ebooks.pucrs.br/edipucrs/acessolivre/anais/cidu/assets.pdf. Acesso em: 12 ago. 2021.

SAVIANI, D. Formação de professores: aspectos históricos e teóricos do problema no contexto brasileiro. Rev. Bras. Educ., v. 14, n. 40, p. 143-155, 2009.

SBPC - SOCIEDADE BRASILEIRA PARA O PROGRASSO DA CIÊNCIA. Carta Presidente do Conselho Nacional de Educação (CNE) sobre BNC-Formação. Disponível em: https://formacao professordotcom.files.wordpress.com/2021/07/of.-sbpc-073-ao-conselho-nacional-de-educacao.pdf. Acesso em: 10 ago. 2021. de agosto de 2021.

SCHEIBE, L. A formação pedagógica do professor licenciado: contexto histórico. Perspectiva, Florianópolis, v. 1, n. 1, p. 31-45, 1983.

SCHNEIDER, M. P. Diretrizes Curriculares Nacionais para a Formação de professores da Educação Básica: das determinações legais às práticas institucionalizadas. 2007. 209 f. Tese (Doutorado em Educação) - Universidade Federal de Santa Catarina, Florianópolis, 2007.

SINTRAJUFE/RS - SINDICATO DOS TRABALHADORES DO JUDICIÁRIO FEDERAL NO RIO GRANDE DO SUL. Denuncia Que Pode Fechar Por Falta De Recursos. Disponível em: https://sintrajufe.org.br/ultimas-noticias-detalhe/universidade-federal. Acesso em: 12 ago. 2021.

STEFANI, L. S.; AGUIAR, J.; HONÓRIO I. C. O papel do gestor público diante da crise gerada pelo corte de verbas na educação no ano de 2019: Estudo de caso do Campus Garopaba do Instituto Federal de Santa Catarina. 2020. Disponível em: https://repositorio.ifsc.edu.br/handle/. Acesso: 12 ago. 2021. 